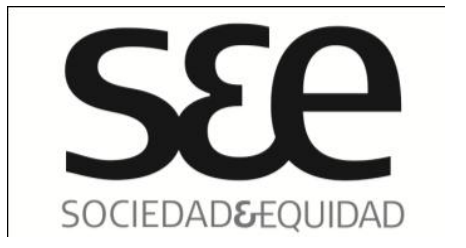

\section{Poner el cuerpo en duda. Interrupciones políticas mediatizadas en Chile}

\author{
Put the body in question. Mediated political \\ disruptions in Chile
}

$\begin{array}{ll}\text { Nombre: } & \text { Cristián Cabello Valenzuela ( }{ }^{1} \text { ) } \\ \text { Filiación: } & \text { Universidad de Chile } \\ \text { País: } & \text { Chile } \\ \text { Correo: } & \text { cristiansereno@gmail.com }\end{array}$

\title{
RESUMEN
}

El cuerpo en la televisión política es aparentemente transparente, no esconde nada. Lo político del cuerpo queda restringido a una superficialidad industrial. Sin embargo, el cuerpo es un espacio de intervención, nunca neutral, y es así como hay momentos donde el cuerpo mediatizado insubordina los códigos de la coherencia y la moral de su territorio. A través de un análisis crítico, este artículo rescata fragmentos de la comunicación política donde el cuerpo pone en entredicho los modos formales, liberales y consensuados del quehacer político. Desde discusiones en torno a la muerte del ex presidente Salvador Allende hasta el análisis de los discursos mediatizados sobre las intervenciones estudiantiles de 2011 en Chile, donde los cuerpos fueron protagonistas, son parte de una mirada crítica desde el feminismo y la comunicación política que busca resaltar la necesidad de lo conflictual en la política mediatizada.

\section{ABSTRACT}

The body on political television is apparently transparent, it does not hide anything. The political aspect of the body is restricted to an industrial superficiality. However, the body is a space for intervention, it is never neutral and there are moments where the mediated body insubordinates codes of coherence and morality in his territory. Through a critical analysis this article rescues fragments of political communication

\footnotetext{
${ }^{1}$ El autor es Periodista de la Universidad de Chile, estudiante de Magíster en Comunicación Política de la misma institución y miembro de la Coordinadora Universitaria por la Disidencia Sexual (CUDS) desde 2006. Líneas investigativas de especialización: comunicación, sexualidades y política.
} 


\section{SEe}

were the body puts into question the formal, liberal and consensual ways of political work. With a critical standpoint departing from feminism and political communication it is sought to highlight the need for the conflictual in media politics. This is done analysing a wide range of media from discussions about the death of the President Salvador Allende to paradoxical arguments about the student protests of 2011 in Chile, where bodies were protagonists.

PALABRAS CLAVES: Comunicación política, cuerpo, liberalismo, representación, feminismo.

KEYWORDS: Communication politics, body, liberalism, representation, feminism.

Hablar de cuerpo en la política siempre supone una cierta incomodidad, un exceso de subjetividad que parece distorsionar el orden "normal” de la propia política. Implica una cierta distorsión, como ocurre en la relación entre mujeres y política, donde estos cuerpos se "vinculan a lo político fallidamente. Vínculo en cuanto solo son el índice de un desorden: el desorden de ser iguales pero estar excluidas de la política" (Castillo, 2011:44). Desde una mirada feminista contemporánea es urgente habitar esta incomodidad política, no remediándola, sino incluso reconociendo lo político ${ }^{2}$ de esta incomodidad, entendiendo la incomodidad del cuerpo como un modo de politizar lo despolitizado de la política.

Justamente consideraremos el movimiento crítico de Michel Foucault al relevar y demostrar la necesidad de comprender los cuerpos no desde una supuesta objetividad o naturaleza, sino comprendiendo sus estudios sobre la normalización de los cuerpos como una vía analítica que "permite tanto desnaturalizar como politizar la sexualidad. Concebida en términos discursivos, la sexualidad puede ser ahora analizada de acuerdo con las estrategias inmanentes de sus operaciones discursivas" (Halperin, 2000:63). Precisamente la relación entre "cuerpo" y "tecnologías de la comunicación" -territorio donde se ubica este texto- hace mucho más complejo el análisis de la política de los cuerpos, porque ya no basta considerar qué dicen o hacen las identidades en la comunicación, sino comprender qué significa este cuerpo que deviene máquina, "el cuerpo como máquina: su educación, el aumento de sus aptitudes (...) y su docilidad, su integración en sistemas de control eficaces y económicos" (Foucault, 2002:168), este cuerpo mediatizado que ya no es un espejo

2 Por lo político comprenderemos un campo más abierto que la política , un territorio no restringido a las identidades cerradas dedicadas a una búsqueda de poder en una orgánica gubernamental, sino que lo comprendemos como "todo aquello que agita lo social con sus múltiples conflictos ideológico-culturales y sus antagonismos de identidad y representación" (Richard, 2008:68). 


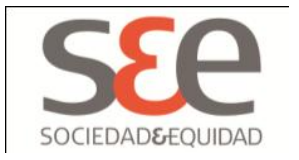

de lo real. Así, por ejemplo, al hablar de la "mujer" en la televisión muchas veces se asimila que la mujer de la representación mediática es similar -si no lo mismo- que la mujer "real", lo cual sigue asumiendo que "la televisión es un espejo de la realidad, que las mujeres y sus estereotipos en televisión se corresponden con los estereotipos de la vida cotidiana" (Cabello, 2011:35). Esto, además de articularse como un error, construiría una metodología del análisis de los cuerpos en la comunicación bajo "una norma humanitaria que excluye los desbordes de los géneros, aspirando a armar más un género sexual oficial y universal, en vez de un género desarmado y localizado, siempre situado" (Cabello, 2011:56).

La relación entre la noción de una representación social y los discursos de la comunicación no son campos idénticos; la identidad de ciertos sujetos no puede encontrarse en la comunicación de modo mimético. El estudio crítico de la comunicación política "no puede partir de una noción dada de sujeto, sino que debe acercarse al sujeto desde los mecanismos, las tecnologías sociales en que éste se construye" (De Lauretis, 1991:54). Acentuamos la mirada en esas tecnologías que sobresalen al momento en que los cuerpos políticos aparecen en la comunicación, esas tecnologías o "modos de aparecer" que señalan lo ficcional de la política. Esta ficción de la política no significa que lo visto sea falso o mentira, sino que interesa reconocer, ya no qué cuerpos están en la representación, sino cuál es el modo de disposición de estos cuerpos, de qué modo toman forma y posición en el espacio público, "lo real es siempre objeto de una ficción, es decir, de una construcción del espacio en el que se anudan lo decible y lo factible” (Rancière, 2010:77).

El interés de este ensayo es reconocer ese desorden en la disposición "normal" de los cuerpos en lo político, lo que denominamos "interrupción política" como modo de señalar un gesto comunicacional (ya no una acción acabada y menos medible en términos matemático-productivos) sin fin determinado. Este modo de mirar el cuerpo en la comunicación -más como un modo de producción que como una cuestión social y biológicamente determinada- supone reconocer sus inestabilidades, “los límites del constructivismo quedan expuestos en aquellas fronteras de la vida corporal donde los cuerpos abyectos o deslegitimados [de la política] no llegan a ser considerados “cuerpos'”. (Butler, 2002:38) ¿Qué es aquello que hace ilegítimos a los cuerpos? La interrupción política de los cuerpos no es una cualidad propia del cuerpo, sino la exposición de un error o falla, la exposición de un cuerpo dañado en su naturaleza comunicacional-social; pero, por sobre todo, es el modo de reencontrarse con lo político de los cuerpos, una cuestión política más próxima al miedo y el terror político que al bienestar de la política. Este ensayo también abarca momentos incómodos de la política, momentos donde la inestabilidad predomina (lo imposible de la política requiere de porciones de irrealidad para su manifestación pública, eso no esperado que se imagina aún como posible) demostrando que cuando "lo irreal requiere realidad o entra en su dominio (...) las normas mismas pueden 


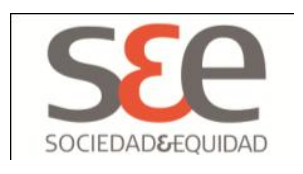

desconcertarse, mostrar su inestabilidad y abrirse a su resignificación" (Butler, 2006:49).

Este ensayo se centra en una observación crítica de los discursos que involucran una comunicación política del cuerpo, un cruce entre biopolítica y comunicación, donde la cuestión política se comprende como un campo donde intervienen múltiples discursos sociales. Principalmente a través del análisis de las intervenciones públicas de los estudiantes de Chile durante el 2011, se analiza el modo en que se mediatizan estas "interrupciones" políticas o "nuevos" modos de habitar la política, pero el objeto principal del estudio es buscar comprender cómo el cuerpo significa y se escenifica en la comunicación política en los momentos donde la política formal es desplazada por el protagonismo del cuerpo. Por lo tanto, a nivel metodológico, no es interés del presente análisis la taxonomización de cuerpos o identidades de la política, ni menos realizar un análisis histórico-político de los sujetos que reconfiguran la política con el protagonismo de un cuerpo-político, sino que comprendemos la comunicación política no "como referencia, no sólo como aparición, no sólo como espectáculo (...) sino (...) como un agente discursivo y un dispositivo de enunciación política” (Arancibia, 2006: 89) donde cuerpo mediatizado es un cruce entre política, economía, cultura, género y clase. Se analizaron casos que aparecieron tanto en prensa como en televisión donde el cuerpo es el objeto que tensiona la política al interrumpir con cierta anomalía de sentidos. Cabe señalar la importancia tanto de la teoría feminista y la teoría biopolítica para comprender las particularidades de las escenificaciones del cuerpo, intentando no hacer una categorización exhaustiva del modo en que aparecen los cuerpos inciertos de la política, sino a través de la comprensión de los significados implícitos de estos discursos sobre el cuerpo que interrumpe la política.

\section{Cuerpos sin duda}

La política tradicional puede abusar de identidades rígidas, de identidades a las cuales se resta el exceso del cuerpo; son cuerpos traducidos como la planicie de una dimensión laboral o técnica. Esto produce superficies despolitizadas por la misma narrativa política. Solo "al ser considerado como una actividad de trabajo, podía esperarse de la acción política [o del cuerpo político] resultados perdurables. Y tales resultados significan paz, la paz necesaria para la contemplación: [es decir,] ningún cambio" (Arendt, 1995:98). Este ensayo busca producir una relectura crítica en contra de la "naturalización de los cuerpos" en la comunicación política. Este proyecto en contra de las tensiones, que busca mantener la normalización, emerge en el uso político comunicacional donde aparecen cuerpos reducidos solo a su dimensión laboral o técnica. Insistente es reconocer y hallar cómo la política -esa que está en busca y posesión del poder "real"- utiliza y explota en su narrativa democrática liberal el caso -particular pero al mismo tiempo general, una especie de 


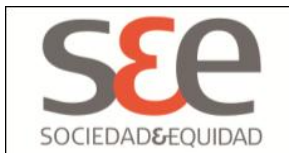

sinécdoque de la política- de la señora esforzada, "trabajadora", la mujer que en el caso de Chile vive en Lampa, Peñalolén o la Pintana, que convive con un cruce desafortunado entre género, clase y raza como sujeto icónico de un cuerpo "otro" supuestamente universal. Así sucedió en un debate en un matinal de televisión entre la senadora UDI designada Ena Von Baer y un dirigente del movimiento universitario de Chile. Para rebatir los argumentos en contra de pensar una educación gratuita la senadora de derecha hizo aparecer el cuerpo de la mujer de clase baja para defender el liberalismo en la educación: "Tú le estás diciendo a los chilenos de familias vulnerables que ellos están obligados a mandar a sus hijos a los colegios municipales (...) yo como senadora puedo elegir al colegio que va mi hijo y puedo mandarlo a un colegio privado, puedo mandarlo a un colegio particular subvencionado y puedo mandarlo a un colegio municipal. ¿Por qué yo puedo elegir y la señora de La Pintana no puede elegir? (...) yo le digo a la señora de La Legua que el Estado hoy le da dinero para elegir"3.

¿Cómo no solidarizar con esa mujer mestiza que aún no logra el progreso? Sin embargo, habría que preguntarse ¿es esa una representación ingenua, solidaria y transparente o es más bien un proyecto donde la experiencia precaria alcanza un rasgo restrictivo y normativo más que polémico? Es significativo cuando este sujeto tipológicamente subalterno es utilizado ya no como una fisura representacional, tampoco como una demostración de desigualdad con la cual comprometerse, sino como un cuerpo útil para hacer desaparecer la duda, un cuerpo que borra los problemas porque aparece como el margen institucional más común y a propósito del cual toma sentido una política donde todos quedan unidos y abrazados bajo el signo de la madre. Sabemos que esta madre sacrificada puede ser cualquier madre, a pesar de que posee rasgos singulares que persuaden en lo emocional y lo transparente; es una generalidad que desarticula diferencias. Cuando se afirma que este cuerpo de la mujer precaria borra la duda en la política, se debe a que el cuerpo de la madre sacrificial posee además un carácter honesto y aparentemente verdadero, por tanto incuestionable en su experiencia. El uso celebratorio y proteccionista de esta iconicidad femenina del Tercer Mundo, es una estrategia ya utilizada por las lógicas coloniales más perversas, como lo señala Spivak: “la imagen del imperialismo como el fundador de una buena sociedad está marcado por la adopción de la mujer como objeto de protección de su propia especie" (Spivak, 2003: 346). Luego se pregunta “Cómo se debería examinar el disimulo de la estrategia patriarcal, que por lo visto le otorga a la mujer libre elección como sujeto?” (Spivak, 2003: 346), justamente porque el discurso político oficial produce en el acto de enunciar a esta "mujer de esfuerzo" a través de una supuesta libertad de elecciones y oportunidades, una "libertad" liberal para constituirse como un sujeto que, en este caso, corresponde a

3 Ver en programa Bienvenidos, Canal 13, disponible en: http://www.youtube.com/watch?v=sWil8-gRTq4\&feature=player_embedded (consultado 20 de agosto de 2011). 


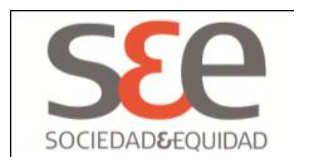

una imagen moral de una buena mujer y una buena madre, asignándole además los roles de dependencia con lo privado y el hogar a la misma mujer que busca nombrar, pero que no desea transformarsu estructura socio-económica ya determinada.

¿Cómo fue que la mujer subalterna, la mujer periférica de Lampa o Peñalolén, se convirtió en nuestra peor enemiga al aparecer como una representación de una diferencia más bien restrictiva y moralizada? La señora de Lampa o La Pintana -esa mujer-ejemplo, esa mujer que no existe sino en su representación- que vive en la pobreza y en la periferia del centro, sirve a la vez como modelo y bandera para una política liberal con valores conservadores. De pronto, ese cuerpo popular de la madre, disuelve diferencias y unifica, se vuelve una representación donde circula el "carácter vacío de significantes que da unidad y coherencia al campo popular" (Laclau, 2008:127), es el sentido común, el símbolo imperioso contra el cual ninguno podría estar en contra pues se convierte en el signo por obviedad correcto, uno que no permea crítica. Esta representación de una mujer abnegada por el "trabajo", demuestra cómo lo particular puede devenir hegemonía a través de un uso universal, "cualquier concepto ideológico de apariencia o alcance universal [en nuestro caso lo popular, el género y lo laboral] puede ser hegemonizado por un contenido específico que acaba “ocupando" esa universalidad y sosteniendo su eficacia” (Zizek, 2009: 14). Ya no es un sujeto popular que se enuncia en contra de una oligarquía poderosa, sino que es una oligarquía política la que enuncia a un sujeto popular de "sexo débil" para neutralizar los conflictos de la misma política. Más aún, es un cuerpo que aparece representado como el más honesto y, por lo tanto, como una experiencia verdadera que debe ser protegida y apoyada por el Estado; es un cuerpo para la conservación que en sus pliegues señala los valores interesados para un Estado liberal y patriarcal.

Debemos dudar cuando la política ocupa identidades y cuerpos para significar un territorio verdadero y auténtico de la experiencia, porque este uso rígido y positivo del cuerpo servirá incluso como imagen corporal de un margen-hegemónico. Debemos dudar de este cuerpo "político" usado por una política populista o incluso liberal, más aún en Latinoamérica, donde "emblematizar este cuerpo-deexperiencias como la única verdad (...) viene a confirmar el estereotipo primitivista de una 'otredad' que sólo cobra vida a través de los afectos y sentimientos" (Richard, 2008: 49).

Es un error pensar y restringir la labor de la política en el deber de procurar reflejar los valores "verdaderos" de una sociedad; esto supondría regresar a una lógica hiperidentitaria, rígida y esencialista. La política debe verificar todo lo contrario porque "lo que realmente está en juego es su transformación" (Mouffe, 1999: 81). De algún modo, este cuerpo femenino-popular que aparece como pura experiencia es un hito en un espacio narrativo político de la neutralidad y la formalidad de la discursividad mediatizada de la política en la pantalla, un suceso donde la política 


\section{s\&e \\ SOCIEDADEEQUIDAD}

habla de un cuerpo específico, localizado y supuestamente problemático (en tanto popular), pero no es menor que este cuerpo signifique solo un sentido común útil discursivamente para borrar las tensiones de lo político. Nos queda entonces solo la posibilidad de dudar de los cuerpos y la naturaleza de sus proyecciones en la pantalla de la comunicación; pensar que los cuerpos ya no son transparentes. El caso de la "señora de Lampa" es útil para comprender cómo las representaciones políticas de los cuerpos que suponemos con mayor autenticidad en la comunicación política, son en realidad modelos que despolitizan la polemicidad de los signos de la comunicación, cuerpos demasiado seguros de sí mismos, que si no se cuestionan permanecerán ininterrumpidos en su tránsito mediático.

\section{Los cuerpos de la comunicación no son transparentes}

Más que confiar en la transparencia y obviedad de lo que dice el cuerpo, debemos pensar sus zonas de incoherencia, sus espacios de des-unión donde es posible el conflicto; debemos poner en duda el cuerpo en tanto se cuestionan sus procesos de naturalización. Esta propuesta no está lejos de cierto pensamiento feminista que se ha dedicado no tanto a construir mecánicamente a la "mujer" sino justamente a poner su cuerpo en un entredicho, incluso desde el "no se nace mujer" sino que "se llega a serlo" de Simone de Beauvoir o cuando Teresa de Lauretis se pregunta "¿qué significa hablar 'como mujer'?" para responderse:

"Para mí, mujer en la historia, los discursos no son coherentes; no hay término específico de referencia, ni un punto certero de enunciación (...) [hay] una irreductible contradicción para las mujeres en el discurso" (De Lauretis, 1991: 61).

De esta manera, se está poniendo en duda una idea política donde la representación a través del cuerpo se considera siempre natural y transparente. La pantalla televisiva ya no es un "espejo de la realidad" para posibilitar la identificación plena. Las contradicciones se articulan como desbordes que nos señalan una zona irregular en la geografía audiovisual de la política.

El cuerpo mediatizado no es una superficie inocua; es el lugar desde donde se articulan discursos políticos que muchas veces buscan otorgar una coherencia moral, un sentido universal, un estatuto de realidad que suele ser visto como un espacio neutro y determinado más aún en el territorio de la política que se autorregula en sus normas y categorías. Esto desconoce que lo real en la comunicación está:

"Totalmente fragmentado: hay tantos "reales" como discursos que se enuncian. En democracia, el juego de la información, como el de lo político, 


\section{SEe}

es un lugar de producción de diferencias. Si esta fragmentación, la mayor parte del tiempo, permanece invisible, es porque cada actor social es llevado a identificar, dentro de la red discursiva, el imaginario que le permite enganchar su creencia” (Verón, 2005: 77).

Sin embargo, el cuerpo cuando circula en pantallas posee la posibilidad constante de perderse y extraviarse en un otro sentido; esto no ocurre tan asiduamente porque se articula la hegemonía de un discurso que busca la coherencia de los cuerpos.

Deleuze ya advertía sobre el acto de higiene política que significa poseer un cuerpo, definirlo o creer que es propiedad del individuo: "Tener un cuerpo es una necesidad moral, una 'exigencia'. Y, en primer lugar, debo tener un cuerpo porque hay algo de oscuro en mí" (Deleuze, 1989: 111). La comunicación mediatizada en el caso de la política busca clasificar y determinar de modo restrictivo los cuerpos; funciona como dispositivo para anular y alejar eso "oscuro" o inestable. Justamente, cuando un cuerpo comienza a perder su sentido, se activan parámetros de ordenación y coordenadas de diagramación en el plano de la comunicación. Así ocurrió cuando el cuerpo de Salvador Allende se puso en duda; no tanto algún rasgo biológico o explícitamente natural, sino cuando tanto él como su muerte se pusieron en duda: ¿Allende se mató con el rifle de su amigo Fidel Castro o, en realidad, los militares lo mataron? ¿Fue parte de la historia de un mártir de izquierda o simplemente fue otro de los cuerpos desaparecidos por el sistema, una cifra más? El doctor Patricio Guijón, quien afirmó que fue el último que vio a Allende con vida y que fue testigo de su suicidio, poco antes del golpe militar en La Moneda, afirmó recientemente que encontró el cuerpo de Salvador Allende, posterior al ataque a La Moneda, "sin cabeza prácticamente, de las cejas para arriba era irreconocible" ${ }^{4}$. En el caso de Allende se desdibuja su identidad de héroe nacional masculino, se pierde el rostro de la identidad, es pura incertidumbre, ya no es un relato unitario y en defensa de lo personal y la historia, no es ese constructo político, ideológico y rígido como señaló su hija al afirmar que "nuestra convicción es que el presidente Allende tomó la decisión de morir como un acto de coherencia política"5. La política mediatizada se afirma en el estatuto de la causa-efecto, de los principios irrevocables, humanistas y masculinos que rigen los movimientos de nuestros cuerpos políticos, de la coherencia normativa de sus prácticas, es el peso de la realidad como

4 Diario La Tercera, Investigación sobre muerte de Salvador Allende siembra dudas sobre la hipótesis de suicidio. Edición 31 de mayo de 2011. (Consultado: 21 de agosto de 2011).

5 lbíd. 


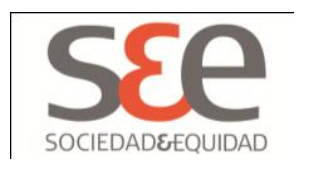

también de la muerte ${ }^{6}$. Impacta cómo la política preestablece una narrativa ordenada y legítima a partir de lo biológico ${ }^{7}$, en cómo la vida es racionalizada por la política, una racionalización que no solo proyecta un discurso universal sino que además impide pensar una reconfiguración de los códigos de la política pues como una estrategia inmunizadora del devenir actúa "apresando todo 'acaso' en la mordaza del 'ya' y el 'aún': del 'siempre-asi' y el 'así-por-siempre’” (Esposito, 2002: 49). La coherencia política y el peso de la realidad práctica impiden reconocer el rasgo ficcional de las historias de la misma política mediatizada, esa ficción entendida como cierta desnaturalización de un sentido hegemónico, la posibilidad de proponer otro sentido. Sin embargo, la relectura de la muerte del ícono de la izquierda demuestra cómo los trazos y cabos de la incoherencia amenazan las lógicas históricas y masculinas que sustentan una lucha política.

La narrativa política unívoca y de lo común es interrumpida en su trayectoria lineal. Se trata de interrupciones que no son al azar, sino que denotan que todo cuerpo político intenta escamotear esas zonas que Deleuze llama "oscuras", a diferencia de un cuerpo que se exhibe con claridad, con una historia coherente, es decir, que produce aceptación o reconocimiento, un sujeto que se deja ver. Sin embargo, la mediatización permite reconocer momentos inclusive donde lo evidente de la política pierde parte de su claridad: es así, por ejemplo, como ciertas protestas estudiantiles expresarían no solo claramente ciertas quejas y demandas ya reconocidas, sino que además abren en su mediatización espectacularizada un pliegue (se despliegan) aparentemente sin sentido -una claridad oscura- para la política y la comunicación en su uso del espacio público más allá de una identidad política liberal que exige sus derechos como estudiantes en la narrativa jurídica. La protesta ya no es tan meramente oposicional (estudiantes contra el Estado) sino que

6 Hay una particular relación y vinculación en el espacio de las representaciones comunicacionales entre realidad y la muerte, más aún en Latinoamérica. Pensemos en el Norte como un territorio que desborda de ciencia ficción y espectacularidad. Sin embargo, en el Sur-Latinoamericano las representaciones de la comunicación en torno a la muerte están aparejadas a una normativa que las aproxima a un peso de la realidad y una exclusión de la parodia y la ficcionalización cuando refiere, por ejemplo, a casos de muerte en contextos de dictadura donde "la 'verdad' del decir, parecen atizar, paródicamente, el deseo de autenticidad, cuerpo, inmediatez, presencia -allí donde la teoría marca su radical imposibilidad-, en definitiva, la valorización exacerbada de todo lo que lleve la impronta de vida real. Los medios de comunicación, ahora globales, son parte esencial de esta tendencia" (Arfuch, 2008: 147).

7 Así lo permite reconocer Donna Haraway cuando verifica cómo el cuerpo es un campo de tensiones políticas mediadas entre biología y tecnologías: "La génesis es un asunto serio, cuando el cuerpo es teorizado como un texto codificado cuyos secretos se revelan sólo mediante las convenciones de lectura apropiadas y cuando el laboratorio parece caracterizarse como un vaso ensamblaje de aparatos de inscripción orgánica y tecnológica (...) El cuerpo es un sistema de inteligencia artificial y la relación entre copia y original es invertida y explotada" (Haraway, 1991: 354). 


\section{S\&e \\ Sresenow}

también permite y produce que lo que antes era claro -la "identidad política" o la "identidad popular"- se confunda y pierda su anterior claridad - "lo claro sale de lo oscuro por un proceso genético" (Deleuze, 1989: 117)- entrecruzándose con otros fragmentos de discursos mediáticos de la cultura, con el mismo cuerpo del dominador o con la interrupción del espacio público.

De algún modo, cuando los estudiantes chilenos intervienen la ciudad a modo de protesta subvirtiendo paródicamente y haciendo "real" una playa en el centro de Santiago para responder a un ministro que adelanta las vacaciones para desarticular las manifestaciones ${ }^{8}$ o, también, la acción de parodiar cierta muletilla del alcalde de la comuna de Santiago, usando la máscara del "enemigo", significa que lo antagónico de la política se extravía en su estrategia discursiva mediatizada: la víctima pasa a ser el victimario y viceversa. En la comunicación política es posible confundir estos códigos para un uso subversivo que demuestra que es posible pensar la política más allá de lo oposicional, que no basta con dos entidades en conflicto, en cuerpos o territorios siempre distintos y distanciados, sino que el conflicto no necesariamente se produce con dos enemigos porque la política ya absorbe y supone como parte de su escenografía el "a favor" y el "en contra", una estrategia oposicional que no necesariamente devela un daño en la política, sino que demuestra su orden. Sin embargo, el giro discursivo está en que la tensión se localiza microscópicamente en un mismo territorio: el cuerpo del estudiante que vibra en la ocupación del rostro de su victimario. Esta acción política de contradicciones, esta acción no-afirmativa, reconoce una política más allá de la mera diferencia, lo que Deleuze ya rescataba al señalar que "la diferenciación no remite a indiferenciado previo, sino a una diferencia que no cesa de desplegarse y replegarse en cada uno de los lados, y que no despliega uno sin replegar al otro, en una coextensividad del desvelamiento y del velamiento del Ser" (Deleuze, 1989: 45).

La claridad coherente de la política se convierte en una divergencia más bien refractaria y que se devela más como un cuestionamiento que como la afirmación política en pos de un éxito. Esta acción que interrumpe el guión de los órdenes tradicionales para pensar la misma política subversiva, desplaza la supuesta neutralidad de la política, haciendo que el acontecimiento político "verdadero" -en tanto objetivo y perceptible de una mirada macroscópica de lo social- pierda su carácter de hecho claro, partidista e institucional y se despliega ahora hacia una acción de lo político que se confunde con la misma cotidianeidad mediatizada.

8 Revisar Diario La Tercera artículo "Alumnos de liceos en toma armaron playa artificial en Plaza de Armas" del 5 de julio de 2011. 


\section{Sce}

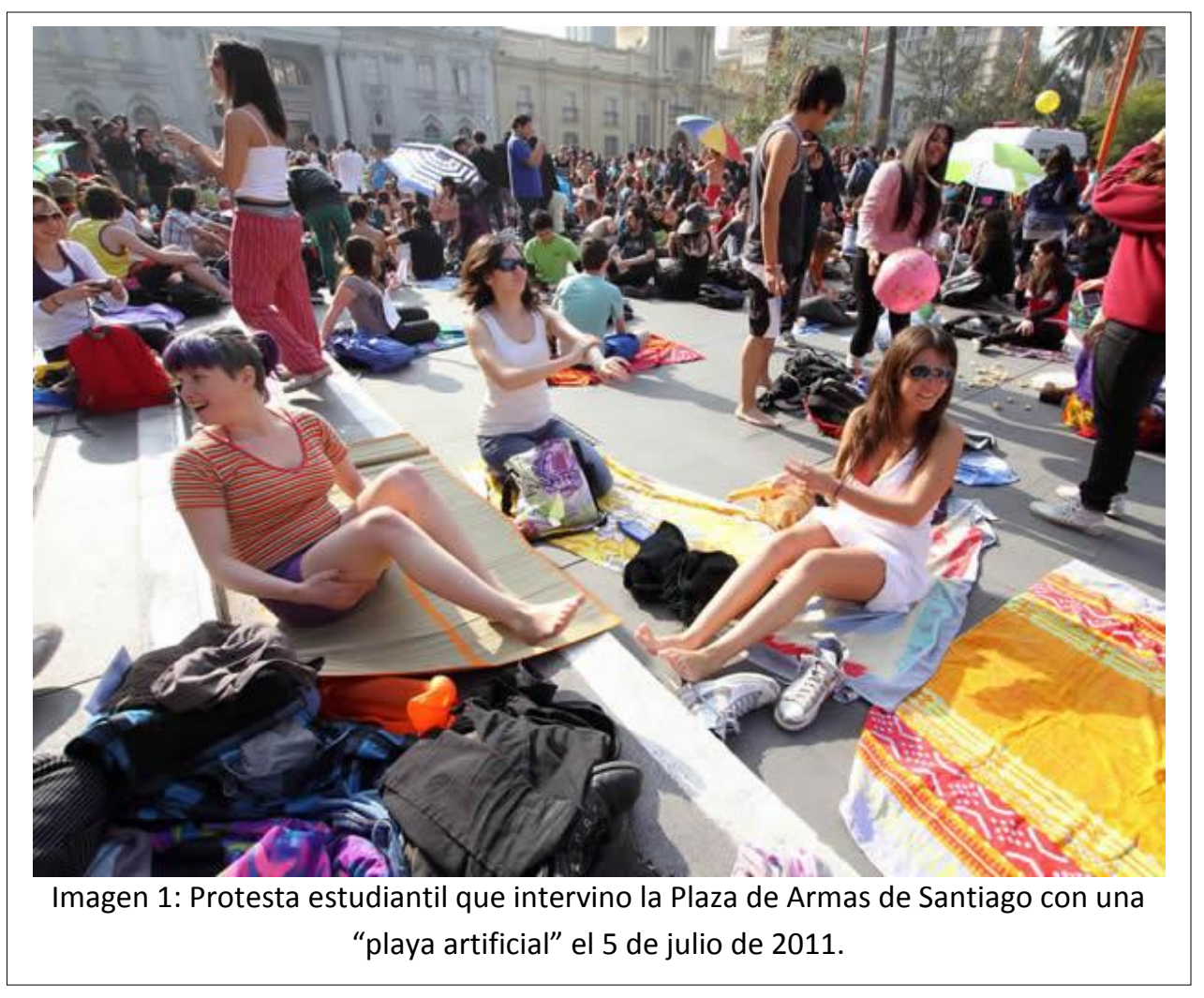

Tenemos la obligación de dudar de todo relato político que se asuma como resuelto o seguro de sí mismo, y más aún si se afirma como un relato verdadero a partir de la experiencia de la vida. La rigidez y permanencia de una verdad política niega las posibles mutaciones simbólicas que ocurran en lo social; anula las transformaciones. Por lo tanto, es importante pensar la potencialidad política de un colectivo de lo social no como la afirmación de un colectivo, sino donde "la identidad del "nosotros" que se crea mediante una forma específica de acción colectiva podría verse en verdad como la pregunta principal" (Mouffe, 1999: 7); más bien, ver el nosotros de la política como una interrogación política sin certeza. Dudar de una unidad política no significa negar una historia, borronear una cierta política en relación con un cuerpo, sino que la duda genera una apertura de la percepción, quizás una focalización porque en la política tradicional se nos acostumbra a mirar el cualquiera, lo común, lo próximo, el proyecto país, una política de grandes acuerdos, transcendente, donde se pierden las particularidades concretas, es decir, y a modo de resumen, se trata de un aprendizaje macroscópico de la política como si ella misma fuera pensada como un universo.

La unidad de la política liberal democrática depende de decisiones "bien pensadas”, de acuerdos en conjunto, es decir, de la relevancia de lo racional. Pero ¿qué ocurre cuando -y más aún en la performance mediática- la política parece comportarse más irracionalmente en sus escenificaciones y constantes interrupciones 


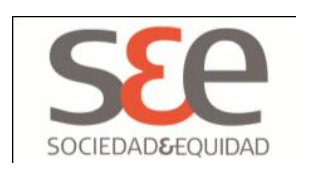

en vez de aparejarse en el plano de lo siempre racional? La lucha estudiantil que arriesga la pérdida del año escolar en búsqueda de su propósito, las protestas que desplazan el lienzo y politizan a íconos pop, o, también, y a modo retrospectivo, una lucha por el voto femenino, son/fueron -qué duda cabe- expresiones que abarcan, en su mediatización pública, un territorio de lo irracional político que produce extrañamiento debido a su producción política "fuera" de los consensos o los modos regulares de pensar y hacer la política.

En agosto, Ministro de Educación del gobierno de Sebastián Piñera realzó despectivamente lo irracional respecto a la demanda estudiantil por una educación gratuita: "No podemos pelear por la educación dejando de educarnos"9 realzando una paradoja y una política del "mal pensar" del movimiento estudiantil en tanto no asisten a clases a modo de protesta. Afortunadamente, hay momentos donde la política no obedece y aparece más bien paradójica e irracional.

Sin embargo, lo irracional político supone una acción en contra de la política y su canon de verdad; es una acción voluntaria que se escribe en otras lógicas que quizás se desean ajenas a la política. ¿Acaso estas acciones descritas y sus cuerpos son absolutamente incomprensibles? Suponer esto significaría legitimar una exclusión y caer en la trampa de una política dicotómica. No se trata de cuerpos o escenas que estén fuera de la política (como si existiera aquello), sino que -parafraseando a Esposito respecto a lo impolítico- "es lo político mismo sustraído de su propia plenitud mítico-operativa" (Esposito, 2006:24). Cuando transgredimos esta racionalidad, se produce por sobre todo una puesta en duda de la veracidad de lo dicho. No es su intención negar a la política, no es su clausura -no es parte taxonómica de la política-, es su posibilidad de duda.

Esta comprensión de lo irracional como un acto de lo político no podría implicar la anulación de la misma política; no importa aquí la excelencia cívica que sabemos ya fracasada, sino develar lo irracional como una fisura de lo político mediatizado que ha sido excluido por un dudoso:

"Humanismo cívico, [que] al mismo tiempo que operaba un desplazamiento de la vida contemplativa a la vida activa, descubría una nueva figura de la razón capaz de crear por medio de la acción un orden humano, político, dando una forma al caos del universo de la contingencia y de la particularidad” (Abensour, 1998: 19).

¿Acaso estas fisuras irregulares no constituyen sino un gesto contrario a la vida contemplativa que permite reconocer las grietas del mismo sistema racional? $Y$

9 Diario Online El Mostrador, edición del 13 de Agosto de 2011. 


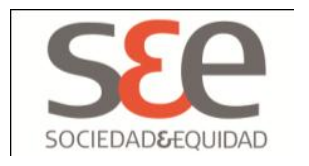

¿cómo lo racional de la política no se ha convertido sino en una comprensión restrictiva para un cuerpo que se desorganiza en lo (in)humano a través de las transformaciones tecnológicas? Comprender la política solo bajo el supuesto de lo racional asume erróneamente que la política es regular, que puede predecirse y que no posee momentos de inestabilidades. Aquí se devela la falla que recalca Mouffe respecto a lo racional, porque no es que estos episodios recién descritos sean inherentemente irracionales o abyectos, sino que existe un marco moral y ético de la política que impide reconocerlos como parte del espacio público en disputa y simplemente los desplaza caracterizándolos negativamente.

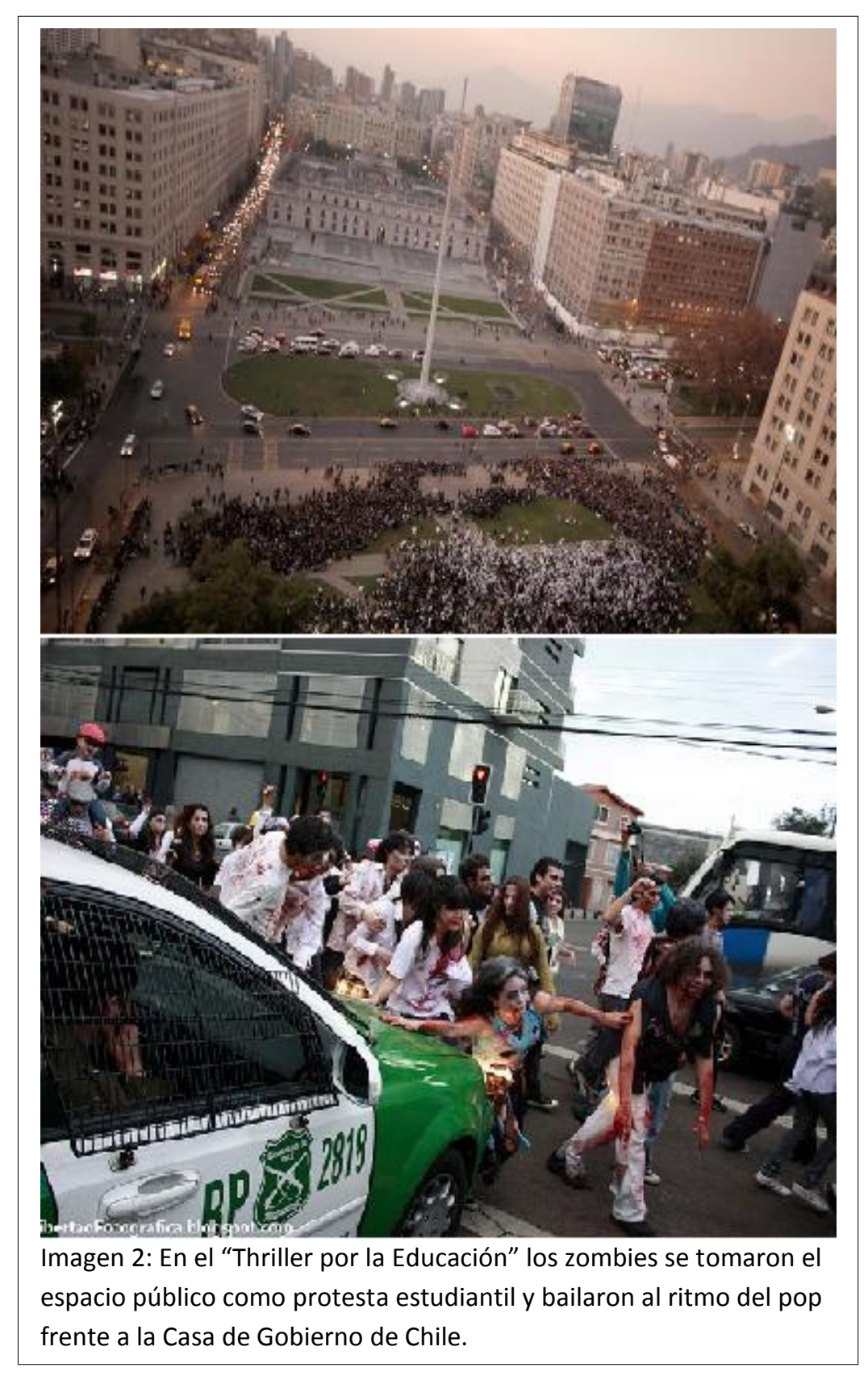




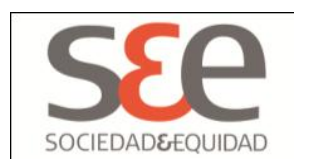

\section{Animalidad política}

La comunicación busca aclarar con taxonomías la tipología del cuerpo en escena. Los dispositivos de la comunicación a través de sus discursos producen un cuerpo con mayor o menor coherencia, pero con un ordenamiento que hace aparecer un cuerpo lógico. La comunicación social busca ese orden; sin embargo, la política en la comunicación es vulnerable a episodios irregulares, es permeable a posibles conflictos. Esto quiere decir que la comunicación política no es un paisaje constituido regularmente, descriptible con anterioridad y, por sobretodo, poseedora de un orden propio de su corpus organizativo. Pero tampoco esto significa pensar la política de la comunicación como una constante y absoluta pérdida de su hegemonía democrática y policial en tanto aparece una representación extraña, irregular e incluso paródica de lo común político. Interesa resaltar ese momento más bien irracional o inesperado donde la política de la comunicación es interrumpida en su transmisión coherente, en sus cuerpos regulares y en su regularidad informativa con apariciones ${ }^{10}$ que ponen en tensión y duda la normalidad del terreno de la política mediatizada.

No debemos engañarnos con la posibilidad heroica de estas inflexiones que se generan en la normalidad política; la narrativa política moralizante buscará administrar estos cuerpos a través de algo de lo cual "se debe hablar como de algo que no se tiene, simplemente, que condenar o tolerar, sino que dirigir, que insertar en sistemas de utilidad, regular para el mayor bien de todos" (Foucault, 2002: 34), es decir, normativizar a través de una visibilización pública. Así ocurrió también con la racionalización que realizaron los discursos públicos de la comunicación que decidieron comprender (y hacer útil) las protestas estudiantiles de 2011; intervinieron la ciudad capital de Chile, resinificándolas más como un acto creativo, pero por sobre todo como una acción política pacífica. Lo que de algún modo significa despolitizar la misma acción en tanto se le niega cualquier queja o conflicto en su experiencia mediatizada o en sus cuerpos aparecidos.

Sin embargo es importante destacar, ya no lo oficial de una política que posee un sistema predecible en sus prácticas, ni tampoco leyendo un sistema que se verifica en los diálogos de lo común, sino realzar aquellos cortocircuitos o apariciones donde miramos desde la perplejidad de no reconocer claramente el por qué de la interrupción de los cuerpos en escena, donde la causa-efecto racionalista se ve vulnerada por una reflexividad y una duda ante estos cuerpos. Una acción política que no posee un fin determinado sino que rescata los cabos sueltos, lo

10 Afortunado es el pliegue de significados del concepto aparición aplicado a una política que reconoce las interrupciones como constitutivas del orden político, ya que en su polisemia indica una cierta y débil representación de un cuerpo, es decir, una constante experiencia de una posibilidad de pérdida, y además señala la existencia de una imagen fantasmagórica que viene y se va, que no es constante, sino más bien sorprendente. 


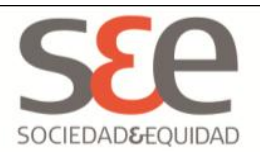

inesperado-político donde una "acción, [que] a pesar de que puede tener un comienzo definido, nunca tiene (...) un fin predecible" (Arendt, 1995: 99). Esta incertidumbre que rescata Arendt es en pos de una política distante de las mecanicidades y la burocracia, una respuesta crítica a una democracia más bien cerrada. Esta acción política abierta que se imagina Arendt, no es una nueva política y menos una "alternativa" más de las tantas que ofrece y se esmera en poseer "a la carta" la democracia pluralista liberal, sino que es más bien una condición salvaje de la política, su afuera mismo que sin embargo está al interior de su mismas fronteras. Sin duda, unos zombies que caminan por Santiago cuestionando el estatuto de la educación o incluso el momento paradójico donde el Estado decide no utilizar las bombas lacrimógenas contra los manifestantes por respeto a la vida del feto, pero solo durante 3 días $^{11}$; no son sino detalles o destellos dentro de una narrativa coherente y racional de la política, un imperfecto no acumulable por la mirada positivista, imposible de leer y agrupar en la memoria de la historia pues no poseen, al parecer, caracteres comunes con otras acciones, porque a fin de cuentas no se consideran acciones políticas porque no se resuelven, no llegan a efectuarse en un fin porque no comprendemos muy bien dónde comienzan y hasta dónde se proyectan. Estas acciones son más bien animales dentro de la política, cuerpos salvajes (no tanto por su naturaleza sino por su relación y circulación en el contexto de la comunicación); este estatuto de animalidad lo encuentra Deleuze en aquellas "pequeñas percepciones [que] son tanto el paso de una percepción a otra como las componentes de cada percepción. Constituyen el estado animal o animado por excelencia: la inquietud" (Deleuze, 1989: 113). Asimismo, la ilusión del "Estado de la razón" surge para "hacer acceder a sus compatriotas, entonces sumidos en el reino animal del espíritu, a la modernidad política, es decir, transfórmalos en un pueblo de ciudadanos" (Abensour, 1998: 30). La democracia se constituye entonces a través de una promesa de modernidad, desarrollo y elevamiento del hombre a través del rechazo de lo animal, ese cuerpo no civilizado.

¿Por qué aislar y excluir estas animalidades de la narrativa políticocomunicacional, si son estas fisuras las que nos permiten reconocer lo desgastado del sistema político pluralista y son estas apariciones comunicacionales las que permiten en su legitimidad remover por momentos las lógicas unificadoras y estáticas de la política? ¿Simplemente las excluiremos de lo político porque son acciones refractarias en la pantalla que no hablan el mismo lenguaje de un sistema democrático de

11 Otra paradójica "acción política" sucedió con la decisión del gobierno de Sebastián Piñera de paralizar el uso de bombas lacrimógenas por posibles consecuencias abortivas que afectarían a las manifestantes que se reprimieron durante las manifestaciones ecologistas realizadas en mayo de 2011. Esta subordinación de la violencia estatal ocurre por posibles causas médicas en defensa del feto o futura vida; solo permaneció vigente por 3 días hasta que se eliminó la duda sobre el "verdadero" daño de estas tecnologías de represión ("Hinzpeter: Bombas lacrimógenas no tienen efectos abortivos ni causan daño a la salud", Radio ADN, 5 de mayo. Disponible en: http: / / www.adnradio.cl/nota. aspx?id=1475829). 


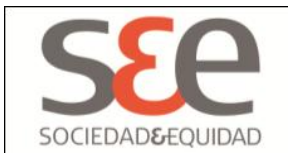

“carácter cívico” que promete la política? ¿Acaso corrompen con su lenguaje paria o paradójico perdiendo el respeto al fundamento discursivo cívico que regula los conflictos políticos de un sistema social donde "la lucha política llevada a cabo de acuerdo con ciertas reglas -cuyo respeto constituye el fundamento de la legitimidad, que hasta ahora no ha sido desmentido a pesar de todo - por el sistema" (Bobbio, 2008: 74)? ¿Qué es la ciudadanía mediatizada, entonces, sino una nueva estandarización de los sujetos y los discursos que estos señalan traducido en "un 'sentido común' ampliamente compartido" (Mouffe, 1999: 81)?

No concederemos pensar que es un hecho que estos episodios más bien casuales y refractarios, que ponen en tensión la narrativa coherente de la racionalización de la política, sean realmente -al ser reconocidos- hitos que destruyan la política en su estructura narrativa cívica. No se trata de una figuración temporal que transgrede los límites del orden político, porque se trata de apariciones dependientes de esa Ley que transgreden, es decir, se trata de no asumir una "transgresión" de manera negativa -anulando a otro-; esto sería desconocer que "el límite y la transgresión se deben uno a otra la densidad de su ser (...) más bien está ligada a él según una relación de espiral con la que ninguna fractura simple puede acabar" (Foucault, 1999: 167-168). No se trata de pensar una transgresión solo a nivel del lenguaje; no es una acción del lenguaje, sino una desviación en el modo de percepción y reflexión de la narrativa política comunicacional.

Estamos ante interrupciones que transitan en un desborde de las imágenes de la televisión, una fractura momentánea del sentido común, la producción de microscópicas partículas de imágenes que hablan de otros y que se ubican en la duda o, como lo señala Valeria Flores, “en el ilimitado campo de la entrelínea (...) [donde] siempre hay más, hay otro, hay otra, hay fractura" (Flores, 2010: 34). Es el "entre" lo que caracteriza apariciones que no indican más que unos cuerpos políticos leíbles fragmentariamente o, justamente, entrelíneas. Es un cuerpo que se pone en duda a sí mismo, asumiendo incluso el riesgo de perder una "legitimidad" propia del reconocimiento político que exige estructura. A pesar de esta ambigüedad, no se conforman cuerpos invisibles o excluidos en un afuera de la comunicación política, sino que interrumpen este flujo con el uso subversivo (no para anular) de las tecnologías y códigos de política mediatizada.

Las interrupciones, además de desbordar la lengua de la comunicación, actúan desde la borradura de la rostridad. Estas acciones de desencaje de la política, si bien pueden poseer y transitar en el uso de ciertos rostros que reflejan por tanto una cierta identidad, no dependen de la obligatoriedad de éstos. El rostro como imagen fundamental de la personalidad política cívica y pública tradicional no es propio de esta fisura de lo político; el rostro pasa a un segundo plano ante el paroxismo del 


\section{SEe}

cuerpo, ante lo obsceno de ese cuerpo que se mira más allá del rostro ${ }^{12}$. Es así como el desplazamiento comunicacional del rostro también indica la hondura y crítica de estas interrupciones, ya que si existe una política que no necesite del rostro, esta es el terrorismo. No cuesta entonces relacionar las fisuras de una política de la interrupción que se desprende del rostro con un micro-terrorismo que Mouffe (siguiendo a Carl Schmitt) define como "el producto de una nueva configuración de lo político que es característica del tipo de orden mundial que se está implementando en torno a la hegemonía de un hiperpoder único" (Mouffe, 2007: 87). El terrorismo es una expresión extrema ante la dificultad de despliegue de otros códigos en la planicie consensuada y a-conflictual, que en nuestro caso se aplican al estado neutralizado de la pantalla mediatizada en Chile. Lo relevante en Mouffe, en su lectura del terrorismo, está en no recriminar esta práctica sino que comprender que su naturaleza es producto de un sistema unificado, hegemónico, que instauran un orden hiperestablecido que en cualquier momento ( $\mathrm{y}$ nuestras interrupciones son un signo) entra en crisis severa; es decir, este terrorismo de desamblaje es producto del propio enemigo que lo crea como un monstruo. Es el terrorismo en tanto un cuerpo sin fronteras muy definidas, un campo sin rostro, una posibilidad para comprender desde un plano "micro" las tensiones que hemos establecido en la política mediatizada.

12 Lo obsceno es comprendido tradicionalmente como aquello que está "fuera de escena", sin embargo esta afirmación podría confundir nuestra argumentación ya que otorga una legitimidad a un "afuera" de la política. Siguiendo a Deleuze, y hasta cierto punto a Foucault, no se trata de un afuera sino de la observación de detalles microscópicos de los cuerpos, observar sus zonas de compresión. Esta mirada del detalle es propia de la escópica pornográfica donde las consecuencias del close-up consolidan la "relegación del nombre propio" como ocurre con la pérdida del rostro de las interrupciones a través de un símil acto pornográfico-tecnológico de "enfocar el funcionamiento, superficies y pliegues de los órganos (...) del cuerpo" (Pavez, 2010: 78). 


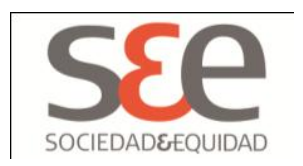

\section{A modo de epílogo: Perder el respeto}

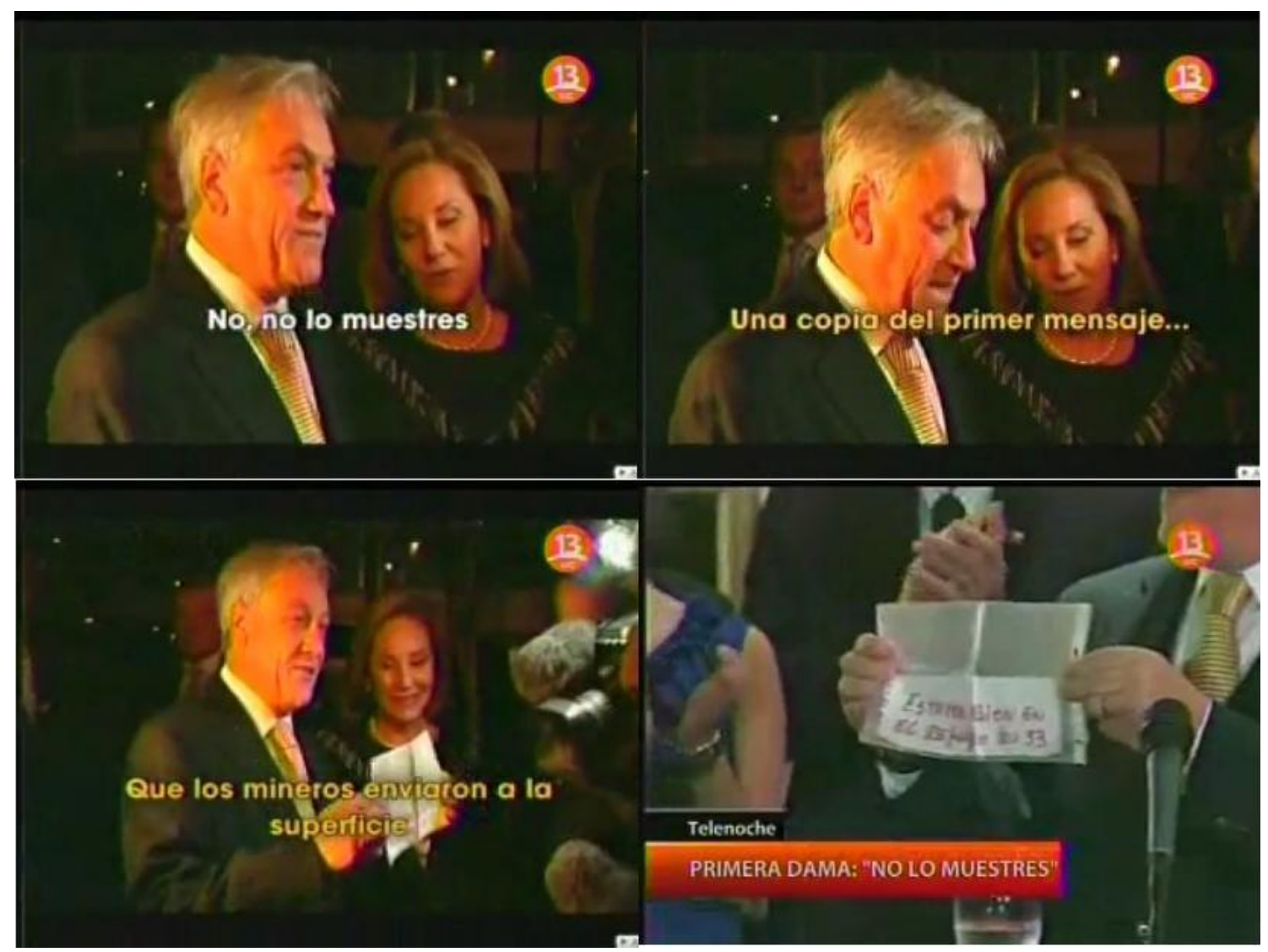

Imagen3: Secuencia de imágenes de nota periodística que cubre el momento en que la primera dama de Chile, Cecilia Morel, muestra su incomodidad frente a su marido durante la gira presidencial de 2011 por Europa (Fuente: Youtube).

A Cecilia Morel le faltan el respeto los medios. El poder en red inesperadamente expone su cruel condición de mujer rubia, primera dama, sumisa y a la vez represiva, y obviamente no escuchada. Morel como el margen, la desplazada que apenas oímos diciendo a su marido "no, no lo muestres". Nos basamos en el extrañamiento que produjo la mediatización del episodio donde la primera dama Cecilia Morel de Piñera es protagonista al intentar reprimir la acción de su marido en una gira presidencial por Europa. La primera dama muestra su desencanto ante la hiper-representación política de un presidente que abusa en todo momento de mostrar el papel-archivo de los mineros, ese trofeo que queda como testimonio de una tragedia y que decía “Estamos bien los 33". Se trata de una mecánica donde la política se expone en su totalidad "para dejarse ver y hacerse presente en su totalidad, su verdad y su destino, y, por lo tanto, de un mundo sin fallas y sin abismos, sin invisibilidad oculta. La representación (...) como producción de verdad” (Nancy, 2006: 42). Morel intentó en un acto fracasado callar el ímpetu discursivo del Presidente, consciente del límite 


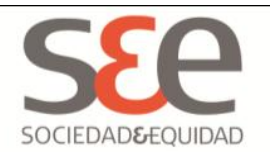

que rozaba la sobre-exposición presidencial de derecha. Lamentablemente, Morel no contaba con la circulación de una grabación no-oficial que captaría ese singular momento donde realiza su queja y donde se permite quebrar la perfecta representación de la gira presidencial.

La primera dama de Chile expuesta con poca dignidad (a pesar de ser una mujer bien vestida, a pesar de seguir siendo rubia). La falta de respeto está en su fracaso de "deseo de dignidad" en tanto mediatización, en su intención por ordenar la representación familiar heterosexual, pero -sin embargo- el reojo de la cámara excepcionalmente expone su susurro escondido, su posición indigna como una mujer no escuchada, una mujer además fuera y lejos del encuadre de las cámaras inglesas, al margen de lo verdaderamente noticioso para la televisión europea. Como mujer de derecha de por sí toda digna convive con esa falla expuesta por la sobremediatización: el hecho de ser esposa, primera dama, ejemplo de sumisión. A Cecilia Morel no la escuchan porque su voz es un susurro autoritario; ella encarna la contradicción de quien pide, quizás, respeto por los desvalidos (los 33 mineros, los pobres, lo que quedó del pueblo). Ella reitera su voz como norma: "no, no lo muestres", el enunciado como el gesto censurador de lo obsceno. Ella que busca respeto pero que quizás también esgrime a la vez su vergüenza clasista por ese papel arrugado; ella, la rubia pudorosa que no quiere ver ese papel que podría ser también en una metáfora psicoanalítica el pene folclórico y vulgar de Piñera, un miembro sorpresivo como el indio pícaro, al cual ella se dirige y afirma tranquilamente: "no, no lo muestres". Sin embargo, ella pierde. Morel exigiendo respeto, un gesto de humanidad de derecha que es sencillamente no escuchado, y aquí se reinstala el sistema paradójico del respeto, ya que quien pedía respeto por su familia y por unos "otros" subalternos y populares, es ahora también la víctima de la falta de respeto a sí misma a través de una inesperada mediatización.

La enunciación del "sin respeto" se identifica o caracteriza como una voz, una queja, una protesta que cruza e interrumpe diversos grupos y subjetividades sociales. Parece una lógica constitutiva de toda aparición que se expone públicamente para poner(se) en tensión -no necesariamente de modo voluntario como ocurre en el caso de la "primera dama"- en sus destellos incoherentes o en su experiencia de extravío fuera de las normas discursivas de la política que no es más que un modo de "encontrarse en lo que excluye (...), experimentar su verdad positiva en el movimiento de la pérdida" (Foucault, 1999: 167). Toda propuesta que reconfigura los códigos o, simplemente, que es resistencia, experimenta la situación del extravío. Esto significa la pérdida del respeto, el poner en duda ese cuerpo.

Al nombrarse un sujeto como "sujeto político", es decir, como el cuerpo de un ciudadano, todo el campo de la acción política desde donde se articula es socializado a partir de los significados del respeto y la tolerancia, lo cual produce un campo protector, una suerte de reconocimiento social. Sin embargo, esta semántica 


\section{SEe \\ sonewas}

jurídica del respeto actúa como un campo despolitizador de lo político que existe en los cuerpos: "el discurso burgués de los derechos no sólo enmascaró, al despolitizarlo, el poder social de instituciones como la propiedad privada o familia, también organizó masas de población para explotarlas y regularlas" (Brown, 2004: 86). Es así, como una paradoja; la búsqueda de dignidad en el espacio de la política es por sí misma un acto no-tan-humano, o mejor aún, un acto que convive con lo indigno al señalar y mostrar su falla públicamente. Hay más y menos tolerados. Asimismo, hay una posibilidad de subversión del habla respetuosa en ese "entre" que ha perdido el respeto. Pero ¿qué ocurre si nos ubicamos política y críticamente frente al respeto? ¿Podemos imaginar entonces una política sin el respeto?

Las acciones mediatizadas señaladas con anterioridad se expresan a través de la ausencia temporal y subjetiva del respeto, lo que implica exponer la vulnerabilidad de la vida señalada en la porosidad entre los cuerpos, porosidad extraña desde una lengua que exige respeto. La política de lo humano y la tolerancia producen la narrativa realista de un cuerpo "propio" dentro de una lógica económica en una nueva 'propiedad'. El sistema económico fácilmente recoge las nuevas identidades y les otorga un perfil seudo-democrático. Por lo tanto es necesario afirmar aquellos fragmentos post-identitarios del flujo político. Es obligatorio, entonces, perder y perdernos el respeto en la proximidad de los cuerpos. Pensar en perder el respeto es como pensarse en una catástrofe. Luego que se tuvo una certidumbre, un nombre propio, se reconoce su temporalidad y ocurre la fractura; se trata de pensar la política sexual desde la catástrofe, como afirma Patricio Marchant, en oposición a una política neo-fascista que privilegia e instala un desarrollismo de los cuerpos, una lógica más de la higiene, donde hay más y mejores ciudadanos. Al tener ciudadanas con más derecho (más postnatales) y con mejor estilo de vida (cuerpos más sanos y más dietéticos) se articula un discurso político que posee una "direccionalidad clara "hacia" el futuro, una línea nítida hacia un punto de llegada certero: la victoria” (Vera, 2009). Este tipo de ciudadanía se narra en una victoria y, como tal, impide reconocer todos aquellos restos y márgenes subjetivos que son obliterados cuando se construye la conquista de lo humano y su cuerpo, y el respeto entre los ciudadanos. El perder(se) el respeto permite reconocer ese campo más incoherente que la política tradicional, ciudadana y democrática no desea leer y reconocer en su mediatización pública. Es una lectura problemática de fallas performáticas que cuestionan el orden de los cuerpos legítimamente políticos. 


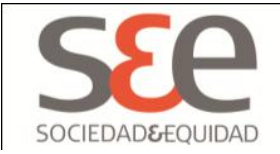

\section{Referencias Bibliográficas}

Abensour, Miguel (1998). La democracia contra el Estado. Buenos Aires: Ediciones Colihue.

Arancibia, Juan Pablo (2006). Comunicación Política. Fragmentos para una genealogía de la mediatización en Chile. Santiago: Editorial ARCIS.

Arendt, Hannah (2005). ¿Qué es la política? Buenos Aires: Editorial Paidós.

Arendt, Hannah (1995). De la historia a la acción. Buenos Aires: Editorial Paidós.

Arfuch, Leonor (2008). Crítica cultural entre política y poética. Buenos Aires:

Editorial Fondo de Cultura Económica.

Bobbio, Norberto (2008). El futuro de la democracia. Ciudad de México: Fondo de Cultura Económica.

Brown, Wendy (2004). "Lo que se pierde con los derechos humanos" en La crítica de los derechos, Uniandes, Bogotá. Pág. 86.

Butler, Judith (2006) .Deshacer el género. Barcelona: Editorial Paidós.

Butler, Judith (2002). Cuerpos que importan. Sobre los límites materiales y discursivos del "sexo". Barcelona: Editorial Paidós.

Cabello, Cristian (2011). Restos de género en la televisión. Subjetividad pública, feminismo y mediatización de la sexualidad. Santiago: Memoria de Título Periodista, Universidad de Chile, Instituto de la Comunicación e Imagen.

Castillo, Alejandra (2011). Nudos feministas. Política, policía, democracia. Santiago: Editorial Palinodia.

De Lauretis, Teresa (1991). Alicia ya no. Feminismo, semiótica y cine. Barcelona: Ediciones Cátedra.

Deleuze, Gilles (1989). El pliegue. Leibniz y el Barroco. Barcelona: Editorial Paidós. Esposito, Roberto (2006) .Categorías de lo impolítico. Buenos Aires: Katz.

Esposito, Roberto (2002). Inmunitas. Protección y negación de la vida. Buenos Aires: Amorrortu Editores.

Flores, Valeria (2010). Deslenguada. Desbordes de una proletaria del lenguaje. Neuquén: Ediciones Ají de Pollo, Colección Conversaciones Feministas.

Fraisse, Geneviève (2011). Del consentimiento. Santiago: Editorial Palinodia.

Foucault, Michel (1999). "Prefacio a la transgresión" en Michel Foucault Entre filosofía y literatura. Obras esenciales. Volumen 1. Barcelona: Editorial Paidós. 


\section{S\&e \\ SOCIEDADEEQUIDAD}

Foucault, Michel (2002). Historia de la sexualidad. La voluntad de saber. Buenos Aires: Siglo Veintiuno Editores.

Halperin, David (2000). San Foucault. Para una hagiografía gay. Buenos Aires: El cuenco de plata/Ediciones literales.

Haraway, Donna (1991). Ciencia, cyborgs y mujeres. La reinvención de la naturaleza. Madrid: Ediciones Cátedra.

Laclau, Ernesto (2008). La razón populista. Buenos Aires: Fondo de Cultura Económica.

Mouffe, Chantal (2007). En torno a lo político. Buenos Aires: Fondo de Cultura Económica.

Mouffe, Chantal (1999). El retorno de lo político. Comunidad, ciudadanía, pluralismo, democracia radical. Barcelona: Editorial Paidós.

Nancy, Jean-Luc (2006). La representación prohibida. Buenos Aires: Amorrortu Editores.

Rancière, Jacques (2010). El espectador emancipado. Buenos Aires: Editorial Manantial.

Richard, Nelly (2008) .Feminismo, género y diferencia(s). Santiago: Editorial Palinodia.

Spivak, Gayatri Chakravorty (2003). “¿Puede hablar el subalterno?” En Revista Colombiana de Antropología, Volumen 39, enero-diciembre.

Pavez, Jorge (2010). "Deseo de clase y violencia sexual" en Archivos Revista de Filosofía, 2009-2010, Santiago: Editorial Universidad Metropolitana de Ciencias de la Educación.

Vera, Antonieta (2009). "Una crítica feminista a la Madre Pública Postdictatorial: los discursos de género en la campaña de Michelle Bachelet" en Revista Nomadías, $N^{\circ} 9$, Santiago: Facultad de Filosofía y Humanidades de la Universidad de Chile y Editorial Cuarto Propio.

Verón, Eliseo (2005). El cuerpo de las imágenes. Bogotá: Editorial Norma.

Zizek, Slavoj (2009). En defensa de la intolerancia. Madrid: Editorial Sequitur. 